\title{
Associations between Initial Change in Physical Activity Level and Subsequent Change in Regional Body Fat Distributions
}

\author{
Kelechi A. Ezekwe ${ }^{a} \quad$ Amanda R.A. Adegboye ${ }^{a} \quad$ Michael Gamborg $^{a}$ \\ Berit L. Heitmann a, b, c, d \\ a Research Unit for Dietary Studies, Institute of Preventive Medicine, Bispebjerg and \\ Frederiksberg Hospitals - Copenhagen University Hospital, Capital Region, Copenhagen, \\ ${ }^{b}$ Research Centre for Prevention and Health, Glostrup University Hospital, Glostrup, \\ Denmark, 'The Boden Institute of Obesity, Nutrition, Exercise \& Eating Disorders, The \\ University of Sydney, Sydney, Australia, ${ }^{d}$ National Institute of Public Health, University of \\ Southern Denmark, Copenhagen, Denmark
}

\section{Key Words}

Body fat distribution · Longitudinal study · Physical activity · Waist circumference $\cdot$ Hip circumference

\begin{abstract}
Background: Few studies have examined which lifestyle factors relate to the development of fat distribution. Therefore, the identification of the determinants of changes in fat deposition is highly relevant. Methods: The association between the change in physical activity (PA) and the subsequent changes in regional body fat distributions was examined. In total, 1,236 men and 1,201 women were included at baseline and participated in the Danish MONICA (MONItoring Trends and Determinants in CArdiovascular Disease) study. A questionnaire was used to assess PA at 5 and 11 years after baseline examination, while waist circumference (WC) and hip circumference $(\mathrm{HC})$ were measured at both follow-ups. Results: Among men, WC increased in the constant active group to a lesser extent than in the non-constant active group (3.4 vs. $4.1 \mathrm{~cm} ; p=0.03$ ) concerning leisure time physical activities (LTPA). A similar pattern was observed for both $W C$ and $H C$ in relation to occupational physical activities (OPA) $(p=$ 0.02). Among women, the results went in the same direction for LTPA, whereas the associations with OPA were in the opposite direction $(p=0.001)$. Conclusion: LTPA and OPA were associated with reduced subsequent 6 -year changes in regional fat distribution for men. For women, no associations were observed in relation to WC; however, OPA seemed to increase $\mathrm{HC}$ among women.


Ezekwe et al.: Associations between Initial Change in Physical Activity Level and Subsequent Change in Regional Body Fat Distributions

\section{Introduction}

Obesity is generally related to an increased mortality and morbidity. In the last couple of decades it has become clear that fat distribution is of particular importance for the general health status [1]. Fat localized in the abdominal region is more strongly associated with cardiovascular diseases [2-4], coronary heart diseases [5, 6], and all-cause mortality [7, 8], whereas fat located in the gluteal-femoral region (peripheral or lower body fat) is found to be protective against these diseases [9-16]. It is therefore relevant to understand how changes in body fat distribution may be modulated. A few studies have shown that physical activity (PA) may influence both total and abdominal adiposity; however, the results from previous studies remain conflicting [17]. Experimental studies have shown that exercise training can reduce adipose tissue [18], and particularly abdominal fat is suggested to be more responsive to exercise than fat in other parts of the body. Therefore, abdominal fat may be more readily mobilized during exercise than peripheral depots [19].

To our knowledge, no previous studies have examined the relationship between PA and lower body regional fat in population-based studies. In this present study, we therefore investigated associations between changes in PA levels over a period of 5 years as well as the subsequent 6-year alterations in waist circumference (WC) and hip circumference (HC).

\section{Material and Methods}

\section{Research Method and Procedures}

The Danish MONICA (MONItoring Trends and Determinants in CArdiovascular Disease) was conducted under the auspices of the World Health Organization (WHO). Random equal-sized samples of 30-, 40-, 50-, and 60-year-old men and women living in the Copenhagen County were drawn from the National Central Person Registry and invited to participate in the study in 1982/83 ( $=4,807)$. The design of the survey has been previously described in detail [20]. After the exclusion of 226 subjects of non-Danish origin, the remaining 4,581 individuals were found to be reasonably representative of the Danish population with respect to sex, age, educational level, occupation, and housing [21]. Individuals who did not respond were again invited by post. Those who still did not respond were contacted by telephone. In total, 3,802 out of 4,581 individuals participated at baseline (1982/83). Five years later (1987/88), 2,990 (79\%), showed-up for a re-examination and 2,536 (67\%) participated in the third examination in 1993/94. Response and nonresponse has been fully described elsewhere [22, 23]. In brief, responders did not differ from non-responders regarding distribution of PA and changes in their regional fat distribution.

This study was approved by the local Ethics Committee for Copenhagen County and was in accordance with the Helsinki Declaration. All individuals gave written informed consent.

\section{Physical Activity Assessments}

Leisure time physical activities (LTPA) and occupational physical activities (OPA) were assessed by employing a self-administered questionnaire that was sent to the participants before their appointed visits to the study centre at baseline (1982/83) as well as at the follow-ups after 5 years $(1987 / 88)$ and after 11 years (1993/94). LTPA was based on answers to the following four alternatives: i) mostly sedentary such as sitting and reading, going to the cinema, and so on; ii) light walking, bicycling, or other light activity for at least $4 \mathrm{~h}$ a week; iii) jogging, demanding sports, or heavy manual work (e.g. gardening) for at least $3 \mathrm{~h}$ a week; and iv) long-distance running or competitive sports several times a week. The first group was defined as inactive and the three other groups were merged into one active group.

OPA was ranked as: i) mostly sedentary - working at desk, little walking around the office, or similar things; ii) light activity - walking around at your place without carrying heavy items such as moderate industrial work, kitchen work, or teaching work; iii) moderate activity - lots of walking such as using the stairs, lifting different things, building houses, and moving around heavy furniture; iv) high activity - very heavy physical work such as digging holes or working in the forest; v) no occupational work.

For the analyses involving OPA, the first and the last group were merged and considered as an inactive group, whereas the remaining three groups were merged and considered as an active group. 
Ezekwe et al.: Associations between Initial Change in Physical Activity Level and

Subsequent Change in Regional Body Fat Distributions

\section{Body Measurements}

Anthropometric measurements were taken at each of the two follow-up health examinations $11987 / 88$ and 1993/94) by a trained nurse in accordance with WHO standards [24]. Body weight was measured to the nearest $0.1 \mathrm{~kg}$ using a SECA balance, with individuals dressed in light clothing or underwear. Height was measured to the nearest $0.5 \mathrm{~cm}$, with individuals wearing no shoes, feet close together, and head held in the horizontal plane. BMI was calculated as weight in kg divided by the square of the height in metres $\left(\mathrm{kg} / \mathrm{m}^{2}\right)$. WC was measured to the nearest $\mathrm{cm}$ midway between lower rib margin and the iliac crest in the horizontal plane. $\mathrm{HC}$ was measured to the nearest $\mathrm{cm}$ at the point yielding the maximum circumference using a tape measure.

\section{Other Variables}

Included in the self-administered questionnaires were lifestyle factors, and for this study, assessment at the first follow-up examination $(1987 / 88)$ was considered. Participants were asked to state their smoking status and current consumption of tobacco in grams per day (g/day): i) never smoker; ii) former smoker; iii) 1-14 g/day; iv) 15-24 g/day; and v) more than $24 \mathrm{~g} /$ day. Alcohol intake was assessed by the average number of beers, glasses of wine, and units of spirit consumed per week and was grouped into seven categories of drinks per week (d/w): i) less than $1 \mathrm{~d} / \mathrm{w}$; ii) between 1 and $7 \mathrm{~d} / \mathrm{w}$; iii) 7-14 d/w; iv) 14-28 d/w; v) 28-42 $\mathrm{d} / \mathrm{w}$; vi) 42-70 d/w; and vii) greater than $70 \mathrm{~d} / \mathrm{w}$. The present study used the number of years of education as an indicator of socio-economic status. Educational attainment was assessed with questions about the years of regular schooling as well as the highest degree achieved and was classified as: i) less than 7 years; ii) between 8 and 11 years; and iii) 12 or more years of education. Women were asked to report whether or not they were pre- or post-menopausal.

\section{Statistical Method}

All analyses were carried out separately for the men and women, representing those who had information of the three points in time of PA measurements and the two points in time of the anthropometric measurements. Statistical analyses were conducted using Stata Statistical Software 10.0 (StataCorp LP, College Station, TX, USA). Mean and standard deviation (SD) were used to describe distribution of age, BMI at baseline (1982/83), WC and HC at both examinations (1987/88 and 1993/94) as well as the changes in WC and HC $(\triangle \mathrm{WC}$ and $\triangle \mathrm{HC})$. The changes were calculated as the differences between the 1993/94 and the $1987 / 88$ examinations. All PA and other categorised variables at baseline and the two follow-ups of PA were presented by their frequencies $(\mathrm{N})$ and percentages (\%).

Multiple linear regressions were used to describe the statistical association between each PA measure and each outcome change, subsequently controlled for possible confounders. In all analyses, both LTPA and OPA levels were grouped into two as the results were essentially similar before and after the collapse of the four groups into two (sedentary and active). Furthermore, studies have shown that regular PA seems effective in reducing cardiovascular morbidity and mortality; this even applies to regular PA with low intensity [25]. For the longitudinal analyses, it was also decided to group the constant active versus the non-constant active. The reason for this grouping is based on the belief that PA behaviour is neither constant nor at the same level over time [26]. In addition, since we had no information about when the subjects had changed from being active to inactive and vice versa during the 5 years of follow-up, we decided to use the simpler grouping of stable active versus others. Finally, similar findings were observed in both analyses, i.e. whether the two groups that changed activity were mixed with the stable inactive group, as found, or when just comparing stable active with stable inactive.

The purpose of this study was to investigate the associations between changes in PA levels between baseline (1982/83) and the follow-up 5 years later (1987/88) versus changes in WC and HC between the examinations in 1987/88 and the follow-up period 6 years later (1993/94). This study represents the classical longitudinal analysis and compares the development in fat distribution of those who constantly remained active over a period of 5 years with those who did not maintain activity during the same time span. Thus, the influence of remaining active over a period of 5 years on the changes in fat distribution during the subsequent 6 years can be examined. Furthermore, in order to clearly understand the influence of remaining active on body fat distribution over a period of time, a classical prospective analysis was also conducted, using one-point PA measurement of 1987/88 to examine the same changes in fat distribution during the subsequent 6 years. Specifically, we examined two groups: those who remained active at both examinations were considered to be in the constant activity group, while the non-constant activity group was the combination of those who were inactive at either points or both points between the two examinations in 1982/83 and 1987/88. A difference test between the groups by means of analysis of variance compared the constant activity group and the non-constant activity group. 
Ezekwe et al.: Associations between Initial Change in Physical Activity Level and

Subsequent Change in Regional Body Fat Distributions

General linear models were constructed to examine the associations between each $\triangle \mathrm{PA}$ and $\triangle \mathrm{WC} / \triangle \mathrm{HC}$. Model 1 accounted only for age, the other anthropometric measures and a mutual adjustment for either LTPA or OPA at baseline. LTPA or OPA was included to eliminate confounding from regression to the mean [27]. Model 2, in addition to model 1, considered relevant covariation from potential confounders such as smoking status, social economic status, alcohol intake, and menopausal status (only for women). Finally, model 3 included model 2 and covariation from attained PA concurrent with the change in fat distribution. This latter model, while deviating from a true longitudinal model, examines the influence of constantly remaining active over 5 years on the change in fat distribution in the subsequent 6 years which is independent of both attained activity levels.

Furthermore, in order to achieve easily interpretable estimates from multiple linear regressions, all models were constructed by suppressing the constant term. In all models, the chosen parameterization did not include a reference group. In the adjusted analyses, confounders were used as the differences from their respective mean values, implying that the adjusted means were interpreted as the mean for a person with an average value of the covariates. All analyses were adjusted for age. The results were expressed as means with a $95 \%$ confidence interval (CI) obtained from the regression analyses, and the level of significance was 0.05 .

\section{Results}

Table 1 shows the general characteristics of the population stratified by gender. In addition, mean and standard deviation (SD) values of WC and HC as well as their changes during the subsequent 6-year follow-up period were included. Mean age did not differ between men and women, whereas mean changes of WC and HC were lower in men than in women and were both significant.

Among men, this classical longitudinal analysis showed that those who remained constantly active over the previous period of 5 years attained a smaller subsequent mean gain in WC compared to those who were non-constantly active ( 3.4 vs. $4.1 \mathrm{~cm} ; \mathrm{p}=0.03$ ) (table 2). Among women, a weaker association with lesser mean gain that disappeared in the final adjustment was found (table 2); however, the results went generally in the same direction as for the men.

Unlike the result for $\triangle \mathrm{WC}$, the longitudinal analysis showed no association between changes in the previous 5-year LTPA and the preceding 6-year changes in HC for either men or women.

Associations between initial change in OPA and subsequent $\triangle \mathrm{WC}$ were in the same direction as for change in LTPA for men, but not for women. Among men, those who had maintained a constant OPA during the previous 5 years had a smaller mean gain in their WC as compared to those who were non-constantly active in the preceding 5 years of OPA (4.0 vs. $4.7 \mathrm{~cm} ; \mathrm{p}=0.02$ ) (table 3). Among women, the association between changes in OPA and $\triangle \mathrm{WC}$ were non-significant.

Unlike the association with change in LTPA, change in OPA was associated with subsequent 6-year changes in $\mathrm{HC}$ for both men and women. Among men, those who were constantly active in their workplaces over 5 years showed a significantly $(p=0.02)$ smaller mean gain in $\mathrm{HC}$, whereas among women, associations were in the opposite direction (table 3). For women, a mean increase in HC over the 6-year follow-up period was greater for those who remained active at work during the previous 5 years.

Furthermore, in the final model for men, the prospective analysis of using each activity measurement at the 5-year follow-up to assess the changes at the follow-up 6 years later showed that the association between LTPA and $\triangle \mathrm{WC}$ had a tendency towards a larger mean gain among subjects from the inactive group than among those from the active group (4.2 vs. $3.4 \mathrm{~cm} ; \mathrm{p}=0.06$ ). Among the women, the association between OPA and $\triangle \mathrm{HC}$ showed a larger mean gain in the active group compared to the inactive group ( $3.8 \mathrm{vs} .3 .1 \mathrm{~cm} ; \mathrm{p}=0.01$ ) (results not shown). 
Ezekwe et al.: Associations between Initial Change in Physical Activity Level and Subsequent Change in Regional Body Fat Distributions

Table 1. Descriptive statistics at baseline and follow-up variables by gender (mean, SD)

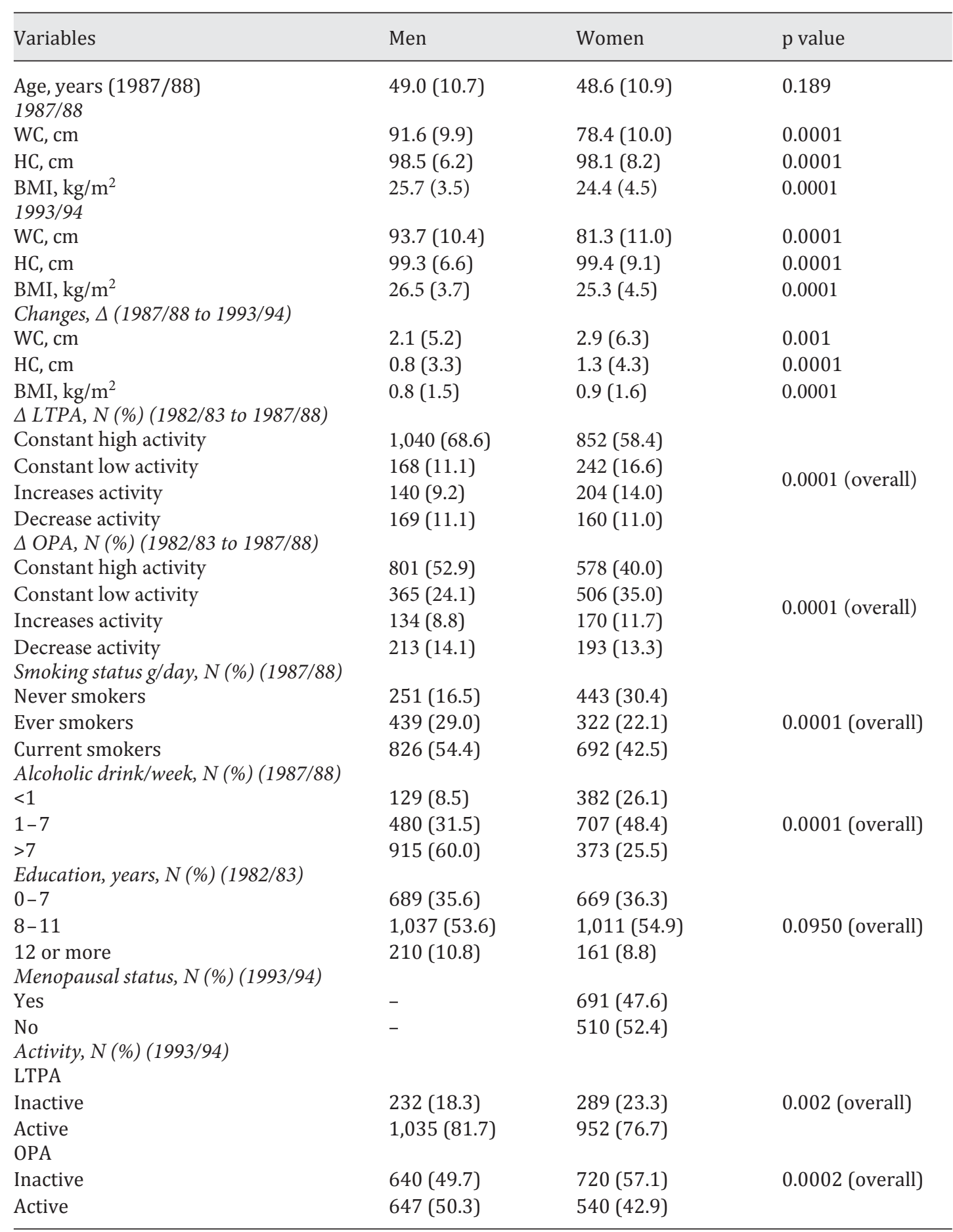

WC = Waist circumference; HC = hip circumference; LTPA = leisure time physical activity; OPA = occupational physical activity. 
Ezekwe et al.: Associations between Initial Change in Physical Activity Level and Subsequent Change in Regional Body Fat Distributions

Table 2. Subsequent 6-year changes in WC and HC among men and women with non-constant and constant previous 5-year leisure activity

\begin{tabular}{|c|c|c|c|c|c|c|c|}
\hline \multirow[t]{2}{*}{ Models } & \multirow[t]{2}{*}{$\mathrm{N}$} & \multicolumn{3}{|c|}{$\Delta \mathrm{WC}, \mathrm{cm}(95 \% \mathrm{CI})^{\mathrm{a}}$} & \multicolumn{3}{|c|}{$\Delta \mathrm{HC}, \mathrm{cm}(95 \% \mathrm{CI})^{\mathrm{a}}$} \\
\hline & & $\begin{array}{l}\text { non-constant } \\
\text { active \& inactive }\end{array}$ & constant active & $\mathrm{p}$ value & $\begin{array}{l}\text { non-constant } \\
\text { active }\end{array}$ & constant active & p value \\
\hline \multicolumn{8}{|l|}{ Men } \\
\hline Model $1^{\mathrm{b}}$ & 1,232 & $3.5(2.7 ; 4.4)$ & $2.5(1.7 ; 3.2)$ & $0.001^{\mathrm{e}}$ & $0.3(-0.2 ; 0.9)$ & $0.3(-0.5 ; 0.5)$ & 0.15 \\
\hline Model $2^{c}$ & 1,219 & $3.4(2.5 ; 4.2)$ & $2.4(1.5 ; 3.2)$ & $0.003^{\mathrm{e}}$ & $0.2(-0.4 ; 0.8)$ & $-0.1(-0.6 ; 0.4)$ & 0.17 \\
\hline Model $3^{\mathrm{d}}$ & 1,200 & $4.1(2.9 ; 5.4)$ & $3.4(2.0 ; 4.7)$ & $0.03^{\mathrm{e}}$ & $0.6(-0.2 ; 1.4)$ & $0.5(-0.4 ; 1.3)$ & 0.52 \\
\hline \multicolumn{8}{|c|}{ Women } \\
\hline Model $1^{\mathrm{b}}$ & 1,197 & $0.5(-0.4 ; 1.4)$ & $-0.3(-0.6 ; 1.2)$ & $0.02^{\mathrm{e}}$ & $2.8(2.1 ; 3.4)$ & $2.4(1.8 ; 3.1)$ & 0.16 \\
\hline Model $2^{c}$ & 1,180 & $0.2(-0.8 ; 1.2)$ & $-0.5(-1.5 ; 0.4)$ & $0.05^{\mathrm{e}}$ & $2.6(1.9 ; 3.3)$ & $2.1(1.4 ; 2.8)$ & 0.10 \\
\hline Model $3^{\mathrm{d}}$ & 1,156 & $0.001(-1.4 ; 1.5)$ & $-0.4(-2.0 ; 1.2)$ & 0.30 & $3.6(2.5 ; 4.6)$ & $3.5(2.3 ; 4.6)$ & 0.72 \\
\hline
\end{tabular}

${ }^{\mathrm{a}}$ The mean $(95 \% \mathrm{CI})$ is the adjusted mean change in WC $(\mathrm{cm})$ and $\mathrm{HC}(\mathrm{cm})$ in both the non-constant active and constant active groups and different levels.

${ }^{\mathrm{b}}$ Adjusted for age, baseline (WC or HC), BMI, and OPA.

${ }^{c}$ Adjusted for the same variables as in model 1 as well as for alcohol, smoking, education, and, in women, menopause status.

${ }^{\mathrm{d}}$ Adjusted for the same as in model 2 as well as for LTPA and OPA at the second follow-up.

e $\mathrm{p}$ value of analysis of variance (ANOVA) test $\leq 0.05$.

WC = Waist circumference; $\mathrm{HC}=$ hip circumference; $\mathrm{LTPA}=$ leisure time physical activity; OPA = occupational physical activity.

Table 3. Subsequent 6-year changes in WC and HC among men and women with non-constant and constant previous 5-year activity during work

\begin{tabular}{|c|c|c|c|c|c|c|c|}
\hline \multirow[t]{2}{*}{ Models } & \multirow[t]{2}{*}{$\mathrm{N}$} & \multicolumn{3}{|c|}{$\Delta \mathrm{WC}, \mathrm{cm}(95 \% \mathrm{CI})^{\mathrm{a}}$} & \multicolumn{3}{|c|}{$\Delta \mathrm{HC}, \mathrm{cm}(95 \% \mathrm{CI})^{\mathrm{a}}$} \\
\hline & & $\begin{array}{l}\text { non-constant } \\
\text { active }\end{array}$ & constant active & $\mathrm{p}$ value & $\begin{array}{l}\text { non-constant } \\
\text { active }\end{array}$ & constant active & $\mathrm{p}$ value \\
\hline \multicolumn{8}{|l|}{ Men } \\
\hline Model $1^{\mathrm{b}}$ & 1,230 & $4.6(3.5 ; 5.6)$ & $3.8(2.8 ; 4.9)$ & $0.01^{\mathrm{e}}$ & $0.8(0.1 ; 1.5)$ & $0.4(-0.3 ; 1.1)$ & $0.02^{\mathrm{e}}$ \\
\hline Model $2^{c}$ & 1,221 & $4.5(3.4 ; 5.6)$ & $3.7(2.6 ; 4.8)$ & $0.01^{\mathrm{e}}$ & $0.7(0.03 ; 1.5)$ & $0.3(-0.4 ; 1.0)$ & $0.02^{\mathrm{e}}$ \\
\hline Model $3^{\mathrm{d}}$ & 1,198 & $4.7(2.9 ; 5.5)$ & $4.0(2.6 ; 5.3)$ & $0.02^{\mathrm{e}}$ & $1.0(0.1 ; 1.8)$ & $0.5(-0.3 ; 1.4)$ & $0.02^{\mathrm{e}}$ \\
\hline \multicolumn{8}{|l|}{ Women } \\
\hline Model $1^{\mathrm{b}}$ & 1,197 & $1.1(-0.1 ; 2.2)$ & $1.2(-0.03 ; 2.4)$ & 0.74 & $2.2(1.4 ; 3.0)$ & $3.1(2.2 ; 4.0)$ & $0.002^{\mathrm{e}}$ \\
\hline Model $2^{c}$ & 1,180 & $0.9(-0.3 ; 2.1)$ & $1.0(-0.3 ; 2.3)$ & 0.78 & $2.3(1.5 ; 3.1)$ & $3.1(2.2 ; 4.0)$ & $0.002^{\mathrm{e}}$ \\
\hline Model $3^{d}$ & 1,156 & $0.03(-0.5 ; 1.6)$ & $0.6(-1.5 ; 1.8)$ & 0.73 & $3.2(2.1 ; 4.3)$ & $4.1(2.9 ; 5.3)$ & $0.001^{\mathrm{e}}$ \\
\hline
\end{tabular}

${ }^{\text {a }}$ The mean $(95 \% \mathrm{CI})$ is the adjusted mean change in WC $(\mathrm{cm})$ and $\mathrm{HC}(\mathrm{cm})$ in both the non-constant active and constant active groups and different levels.

bAdjusted for age, baseline (WC or HC), BMI, and LTPA.

${ }^{c}$ Adjusted for the same variables as in model 1 as well as alcohol, smoking, education, and, in women, menopause status.

${ }^{\mathrm{d}}$ Adjusted for the same as in model 2 as well as LTPA and OPA at the second follow-up.

${ }^{\mathrm{e}} \mathrm{p}$ value of analysis of variance (ANOVA) test $\leq 0.05$.

$\mathrm{WC}=$ Waist circumference; $\mathrm{HC}=$ hip circumference; $\mathrm{LTPA}=$ leisure time physical activity; OPA = occupational physical activity. 
Ezekwe et al.: Associations between Initial Change in Physical Activity Level and Subsequent Change in Regional Body Fat Distributions

\section{Discussion}

In general, our analyses confirmed that subjects with a high constant PA during leisure time, but not at the workplace, increased their WC less than subjects who were inactive or had an unstable activity [28]. These associations were particularly evident among men while no significant effects were observed among women. However, associations with HC, particularly a high constant activity during work but not during leisure times, were related to smaller mean gain in hip size among men. A high constant activity among women was associated with a larger mean gain in HC. The reason for this difference between men and women remains unknown. Also, although different hormonal factors may play a role in the different findings in men and women, the possibility remains that the observed gender difference may simply be a chance finding. However, gain in circumferences may be due to a gain in fat and/or muscle, which may be gender-specific. Also, work-related high activity may be different in intensity, duration, and velocity for men and women.

Furthermore, the gender-specific differences observed in the associations between change in LTPA and subsequent change in WC in this study may be related to the genetic differences in fat mobilization [29-31]. Indeed, some studies have suggested that the male fat patterning may be more responsive to PA than female fat patterning as men tend to lose more fat centrally in response to exercise than women [32]. This does not mean that activity is unimportant for women, and this present study suggests that maintaining high constant activity over 5 years may result in less waist mean gain also for the women.

Moreover, men and women tend to engage in different types of activities in general; e.g., women are more likely to be engaged in activities with lower intensities or a more readily reported set of activities [33,34]. In addition, it should be noted that PA may have a specific effect on morphological and functional parameters only under certain conditions (e.g. degree of intensity, frequency, and duration). However, we did not have such information available. On the one hand, the lack of such precise information may have led to an attenuation of some of our observed associations, and we may have overlooked significant relations. On the other hand, it may also be assumed that those associations we did identify would have been stronger if we had such information available. LTPA associations with both WC and HC may have been obscured by the use of crude data of PA, which was not sensitive enough to detect associations particularly for the women. In this context, it cannot be excluded that men may perceive more social pressure to overreport their activity levels than women.

Finally, the observed gender-specific associations may also be at least partly attributable to differences in the self-reporting of PA levels by men and women [35]. Although it has been found out that exercise without weight loss was associated with a substantial reduction in total fat and fat around the waist [36], studies examining the association of a change in PA with lower body fat or of a change in this compartment are generally absent from the literature.

In line with our results was a twin study by Waller et al. [37] which reported that persistent participation in LTPA was associated with reduced WC among adults. However, their study generally investigated whether associations were independent of genes and childhood environment and did not specifically focus on the effect of PA on regional fat distribution per se. Also, Sternfeld et al. [38] reported, among a group of middle-aged women, that maintaining or increasing regular activity seemed to prevent or attenuate gain in their waistlines.

The major strength of the present study includes the longitudinal design and the use of a large homogeneous population. One limitation is the lack of information on the changes occurring in the different tissue compartments in the waist and hip regions as we cannot examine whether these changes occurred for fat or muscle. Furthermore, our inability to adjust for dietary/energy intake may have influenced our results. 
However, our observations do have some important clinical implications as abdominal body fat is closely related to metabolic and cardiovascular diseases [14, 39], and gluteofemoral mass may protect against the same chronic diseases [12, 16, 40]. In addition, recent reviews have shown that a low HC seems to be associated with an increased risk of cardiovascular morbidity and mortality $[39,41]$; thus, a large HC was considered beneficial in the present study.

This present study supports the ongoing challenge faced by public health professionals of developing effective strategies to promote and support maintenance of regular leisure time activity. From the public health perspective, the strong finding to emerge from this study is the extent to which active lifestyle at either leisure or workplace reduces WC. Therefore, conflicting and opposite findings for $\mathrm{HC}$ among men and women need further examination.

In conclusion, both LTPA and OPA seem to be associated with reduced changes in regional fat distribution in men during the subsequent 6 years. For women, the associations were weaker, and activity at the workplaces seemed to increase $\mathrm{HC}$ among women. Further studies are required to clarify the responsible factors for the gender differences.

\section{Disclosure Statement}

The authors declared no conflict of interest.

\section{References}

$>1$ Georges E, Mueller WH, Wear ML: Body fat distribution in men and women of the Hispanic health and nutrition examination survey of the United States: associations with behavioural variables. Ann Hum Biol 1993;20: 275-291.

-2 Chan LC, Ware RS, Kesting J, Marczak M, Good D, Shaw JT: Association between anthropometric measures of obesity and cardiovascular risk markers in a self-selected group of indigenous Australians. Eur J Cardiovasc Prev Rehabil 2007;14:515-517.

-3 de Koning L, Merchant AT, Pogue J, Anand SS: Waist circumference and waist-to-hip ratio as predictors of cardiovascular events: meta-regression analysis of prospective studies. Eur Heart J 2007;28:850-856.

4 Esmaillzadeh A, Mirmiran P, Azizi F: Evaluation of waist circumference to predict cardiovascular risk factors in an overweight Tehranian population: findings from Tehran Lipid and Glucose Study. Int J Vitam Nutr Res 2005;75:347-356.

5 Rexrode KM, Carey VJ, Hennekens CH, Walters EE, Colditz GA, Stampfer MJ, Willett WC, Manson JE: Abdominal adiposity and coronary heart disease in women. JAMA 1998;280:1843-1848.

6 Rexrode KM, Buring JE, Manson JE: Abdominal and total adiposity and risk of coronary heart disease in men. Int J Obes Relat Metab Disord 2001;25:1047-1056.

7 Bigaard J, Frederiksen K, Tjonneland A, Thomsen BL, Overvad K, Heitmann BL, Sorensen TI: Waist circumference and body composition in relation to all-cause mortality in middle-aged men and women. Int J Obes (Lond) 2005;29:778-784.

8 Bigaard J, Christensen J, Tjonneland A, Thomsen BL, Overvad K, Sorensen TI: Influence of lifestyle aspects on the association of body size and shape with all-cause mortality in middle-aged men and women. Obes Facts 2010;3:252-260.

-9 Heitmann BL, Frederiksen P, Lissner L: Hip circumference and cardiovascular morbidity and mortality in men and women. Obes Res 2004;12:482-487.

$>10$ Lissner L, Bjorkelund C, Heitmann BL, Seidell JC, Bengtsson C: Larger hip circumference independently predicts health and longevity in a Swedish female cohort. Obes Res 2001;9:644-646.

11 Chakraborty R, Bose K: Central adiposity, body mass index and percent body fat among Bengalee Hindu male slum dwellers of Dum Dum, West Bengal, India. The Open Obesity Journal 2009;1:32-37. www.benthamscience.com/open/toobesj/articles/V001/32TOOBESJ.pdf.

12 Snijder MB, Dekker JM, Visser M, Yudkin JS, Stehouwer CD, Bouter LM, Heine RJ, Nijpels G, Seidell JC: Larger thigh and hip circumferences are associated with better glucose tolerance: the Hoorn study. Obes Res 2003; 11:104-111.

13 Snijder MB, Dekker JM, Visser M, Bouter LM, Stehouwer CD, Kostense PJ, Yudkin JS, Heine RJ, Nijpels G, Seidell JC: Associations of hip and thigh circumferences independent of waist circumference with the incidence of type 2 diabetes: the Hoorn Study. Am J Clin Nutr 2003;77:1192-1197. 
Ezekwe et al.: Associations between Initial Change in Physical Activity Level and Subsequent Change in Regional Body Fat Distributions

14 Snijder MB, Zimmet PZ, Visser M, Dekker JM, Seidell JC, Shaw JE: Independent and opposite associations of waist and hip circumferences with diabetes, hypertension and dyslipidemia: the AusDiab Study. Int J Obes Relat Metab Disord 2004;28:402-409.

15 Snijder MB, Dekker JM, Visser M, Bouter LM, Stehouwer CD, Yudkin JS, Heine RJ, Nijpels G, Seidell JC: Trunk fat and leg fat have independent and opposite associations with fasting and postload glucose levels: the Hoorn study. Diabetes Care 2004;27:372-377.

16 Snijder MB, Zimmet PZ, Visser M, Dekker JM, Seidell JC, Shaw JE: Independent association of hip circumference with metabolic profile in different ethnic groups. Obes Res 2004;12:1370-1374.

17 Samaras K, Kelly PJ, Chiano MN, Spector TD, Campbell LV: Genetic and environmental influences on total-body and central abdominal fat: the effect of physical activity in female twins. Ann Intern Med 1999;130:873-882.

18 Ross R, Janssen I: Physical activity, total and regional obesity: dose-response considerations. Med Sci Sports Exerc 2001;33:S521-S527.

19 Samaras K, Campbell LV: The non-genetic determinants of central adiposity. Int J Obes Relat Metab Disord 1997;21:839-845.

20 Gerdes LU, Bronnum-Hansen H, Madsen M, Borch-Johnsen K, Jorgensen T, Sjol A, Schroll M: Trends in selected biological risk factors of cardiovascular diseases in the Danish MONICA population 1982-1992 (article in Danish). Ugeskr Laeger 2001;163:6417-6420.

-21 Hollnagel H: The health structure of 40-year-old men and women in the Glostrup area, Denmark - an epidemiological survey. General design, sampling results and referrals for further medical care. Dan Med Bull 1980; 27:121-130.

22 Heitmann BL: Body fat in the adult Danish population aged 35-65 years: an epidemiological study. Int J Obes 1991;15:535-545.

23 Heitmann BL, Garby L: Composition (lean and fat tissue) of weight changes in adult Danes. Am J Clin Nutr 2002; 75:840-847.

24 World Health Organization (WHO): Measuring Obesity - Classification and Description of Anthropometric Data. Report on a WHO Consultation of the Epidemiology of Obesity, Warsaw, 21-23 October 1987. Copenhagen, World Health Organization, 1989/2010.

25 Lollgen H, Volker K, Bockenhoff A, Lollgen D: Physical activity and prevention of cardiovascular diseases (article in German). Herz 2006;31:519-523.

26 Van MW, Twisk JW, Kemper HC, Snel J, Post GB: Longitudinal relationships between lifestyle and cardiovascular and bone health status indicators in males and females between 13 and 27 years of age; a review of findings from the Amsterdam Growth and Health Longitudinal Study. Public Health Nutr 1999;2:419-427.

27 Rothman KJ, Greenland S: Introduction to stratified analysis; in Rothman KJ, Greenland S (eds): Modern Epidemiology. Philadelphia, Lippincott-Raven, 1998, pp 253-279.

-28 Han TS, Bijnen FC, Lean ME, Seidell JC: Separate associations of waist and hip circumference with lifestyle factors. Int J Epidemiol 1998;27:422-430.

-29 Bouchard C: Genetic influences on body composition and regional fat distribution. Bol Asoc Med P R 1991;83: 354-356.

30 Bouchard C, Després JP, Mauriège P: Genetic and nongenetic determinants of regional fat distribution. Endocr Rev 1993;14:72-93.

-31 Bouchard C: Genetic determinants of regional fat distribution. Hum Reprod 1997;12(suppl 1):1-5.

-32 Després JP, Tremblay A, Nadeau A, Bouchard C: Physical training and changes in regional adipose tissue distribution. Acta Med Scand Suppl 1988;723:205-212.

33 National Health and Medical Research Council: Acting on Australia's Weight: A Strategic Plan for the Prevention of Overweight and Obesity. Canberra, AGPS, 1997.

34 United States Department of Health and Human Services: Physical Activity and Health: A Report of the Surgeon General. Atlanta, GA, United States Department of Health and Human Services, Centers for Disease Control and Prevention, National Center for Chronic Disease Control and Prevention and Health Promotion, 1996.

35 Williamson DF, Madans J, Anda RF, Kleinman JC, Kahn HS, Byers T: Recreational physical activity and ten-year weight change in a US national cohort. Int J Obes Relat Metab Disord 1993;17:279-286.

-36 Ross R, Janssen I, Dawson J, Kungl AM, Kuk JL, Wong SL, Nguyen-Duy TB, Lee S, Kilpatrick K, Hudson R: Exercise-induced reduction in obesity and insulin resistance in women: a randomized controlled trial. Obes Res 2004;12:789-798.

37 Waller K, Kaprio J, Kujala UM: Associations between long-term physical activity, waist circumference and weight gain: a 30-year longitudinal twin study. Int J Obes (Lond) 2008;32:353-361.

-38 Sternfeld B, Wang H, Quesenberry CP Jr, Abrams B, Everson-Rose SA, Greendale GA, Matthews KA, Torrens JI, Sowers M: Physical activity and changes in weight and waist circumference in midlife women: findings from the Study of Women's Health Across the Nation. Am J Epidemiol 2004;160:912-922.

-39 Manolopoulos KN, Karpe F, Frayn KN: Gluteofemoral body fat as a determinant of metabolic health. Int J Obes (Lond) 2010;34:949-959.

-40 Snijder MB, Visser M, Dekker JM, Goodpaster BH, Harris TB, Kritchevsky SB, De Rekeneire N, Kanaya AM, Newman AB, Tylavsky FA, Seidell JC: Low subcutaneous thigh fat is a risk factor for unfavourable glucose and lipid levels, independently of high abdominal fat. The Health ABC Study. Diabetologia 2005;48:301-308.

41 Heitmann BL, Lissner L: Hip Hip Hurrah! Hip size inversely related to heart disease and total mortality. Obes $\operatorname{Rev} 2011 ; 12: 478-481$. 